\title{
RECRUITMENT OF A CORAL REEF FISH: ROLES OF SETTLEMENT, HABITAT, AND POSTSETTLEMENT LOSSES
}

\author{
JEFFREY S. SHIMA \\ Marine Science Institute, and Department of Ecology, Evolution, and Marine Biology, \\ University of California-Santa Barbara, California 93106 USA
}

\begin{abstract}
Multiple processes typically influence patterns of abundance. Despite this widely accepted view, many studies continue to approach ecological questions from a singlefactor, or, at most, a two-factor perspective. Here, I evaluate the consequences of considering, separately and jointly, the effects of three factors (larval settlement, reef resources, and postsettlement losses) on spatial patterns of abundance of a marine reef fish, the six bar wrasse (Thalassoma hardwicke). Using correlational methods commonly employed in single-factor studies, I show that local patterns of abundance of juvenile wrasse could be attributed entirely to either (1) patterns of abundance of settlement habitat, or (2) patterns of larval settlement. This result occurred because habitat and presumed larval delivery covaried in space. I manipulated abundance of settlement habitat in a field experiment to uncouple this covariation and found subsequent settlement to be simultaneously influenced by both factors. However, joint effects of habitat and settlement failed to account for patterns of abundance of juvenile wrasse without also considering a third factor-postsettlement losses - which were density-dependent and substantially modified patterns of settlement. These results illustrate (1) how multifactorial explanations may be falsely refuted when incomplete sets of multiple factors are considered, and (2) how single-factor explanations may misrepresent underlying multifactorial causation of ecological patterns. Uncovering the interactive role of multiple factors in determining ecological patterns of interest requires a shift from single-factor approaches to more pluralistic perspectives.

Key words: abundance; components; density dependence; habitat limitation; labrids; multifactorial causation; postsettlement processes; recruitment limitation; coral reef fish; settlement; six bar wrasse; spatial autocorrelation; Thalassoma hardwicke.
\end{abstract}

\section{INTRODUCTION}

Despite broad consensus that multiple processes simultaneously contribute to ecological and evolutionary patterns (Quinn and Dunham 1983, Welden and Slauson 1986, Hixon 1991, Jones 1991, Thomson et al. 1996), studies investigating causation of patterns by single, or, at most, two factors continue to proliferate. The continued reliance upon one- or two-factor explanations for ecological patterns likely stems from the added logistical and statistical difficulties of properly considering effects of more than two factors simultaneously. While studies exploring effects of a single factor in isolation can yield important and useful information (e.g., Connell 1961, Paine 1966), they are often criticized for providing an unrealistic portrait of the relative role of a particular factor in "real world" settings (Herrera 1991, 1992, Houle 1998, Folt et al. 1999). Multiple factors can act additively or synergistically to yield ecological and evolutionary patterns that differ from those predicted solely from the observed effects of a single factor explored in isolation (Herrera 1991, Brody 1997, Folt et al. 1999).

Limitations associated with considering single-factor explanations for ecological and evolutionary patterns

Manuscript received 28 January 2000; revised 23 June 2000; accepted 23 June 2000; final version received 9 October 2000. based on only one or two factors are further compounded when assessments of causality are based on correlational studies. Although experiments are widely championed for their ability to attribute causal relationships, Thomson et al. (1996) note that correlational studies are still important in ecology and are likely to become more so as the number of studies at larger spatial scales increase. However, using such correlational approaches to attribute an ecological pattern (e.g., tree seedling establishment across a gradient of soil moisture) to a single factor (soil moisture) may be misleading, particularly if other unmeasured but important factors (seed deposition rates or seed predation rates) also vary across gradients of that single factor. In this scenario, all factors may contribute to seedling establishment, but commonly employed correlational approaches (and experiments) coupled with a singlefactor mind-set may misrepresent multifactorial causation.

This paper explores these general issues for a reef fish system with demographically open populations, where local population sizes are determined by the joint effects of reef resource availability, larval settlement, and postsettlement losses (Warner and Hughes 1988, Hixon 1991, Jones 1991, Sale 1991, Caley et al. 1996). I consider three major factors that influence local population size, and use correlational approaches com- 
monly implemented by reef fish ecologists (reviewed in Doherty [1991], Williams [1991]) to attribute patterns of abundance to single factors (either reef resources or larval settlement). I then consider the joint effects of reef resources, settlement, and postsettlement losses (i.e., multifactorial causation), and show how their combined effects can also account for patterns of abundance. Results clearly illustrate how a single-factor perspective can mask underlying multifactorial causation.

\section{Methods}

\section{Study site}

This study was conducted on the island of Moorea, French Polynesia $\left(17^{\circ} 30^{\prime} \mathrm{S}, 149^{\circ} 50^{\prime} \mathrm{W}\right)$ during July 1995-August 1997. Moorea is surrounded by a shallow lagoon (1-3 $\mathrm{m}$ deep), which spans from shore to a barrier reef crest located 500-1500 m offshore. Oceanic water containing larvae of reef organisms is supplied to the lagoon by waves that break over the offshore reef crest (Dufour and Galzin 1993, Dufour et al. 1996; J. Shima, unpublished data). This water generally circulates shoreward and eventually exits the lagoon system through breaks in the reef crest (Galzin and Pointier 1985). Reef habitat within the lagoon is composed primarily of small patch reefs $\left(<10 \mathrm{~m}^{2}\right)$, or, less often, of "thickets" of branching staghorn corals (Acropora spp.). Patch reefs are predominantly Porites spp. colonies, but are often surmounted by smaller colonies of other species (Pocillopora spp., Millepora spp., and Acropora spp.). Portions of many patch reefs consist of dead coral skeletons, which may be covered by patches of macroalgae (Turbinaria spp., and Sargassum spp.) or lush stands of filamentous algae (primarily Polysiphonia spp., and Sphacelaria spp.) that are maintained by the territorial damselfish Stegastes nigricans. Patch reefs are separated from one another by low-lying expanses of "reef flat" composed of sand, fine coral rubble, or pavement (cemented coral rubble).

\section{Study species}

The six bar wrasse (Thalassoma hardwicke) is a common resident of the shallow lagoon on Moorea, and is thought to be a protogynous hermaphrodite (R. Warner, personal communication). Adults (8-22 cm in length) forage on invertebrates and eggs of other species over large home ranges $\left(>1000 \mathrm{~m}^{2}\right)$ and spawn pelagic eggs and larvae that settle after $\sim 47 \mathrm{~d}$ in the plankton (Victor 1986a). On Moorea, settlement occurs directly to patch reefs, in pulses spanning five consecutive nights centered around new moons between January and July ( $\mathrm{J}$. Shima, personal observation). New settlers are distinguished from juveniles (one or more days old) by a lack pigment in much of their bodies, and can be accurately censused on small patch reefs. Juveniles remain closely associated with patch reefs for at least six months after settlement, foraging on microinvertebra- tes and sheltering within reef interstices (J. Shima, unpublished data). Although patch reef populations of juvenile wrasse are typically comprised of multiple cohorts from several sequential settlement pulses, cohorts less than four months old can be visually distinguished from one another, and behavioral interactions among individuals are generally limited to within-cohort interactions (Shima 1999a).

\section{Pattern of abundance of juvenile wrasse}

I surveyed abundance of juvenile six bar wrasse within 80 quadrats around Moorea between 11 July 1995 and 28 September 1995, after cessation of seasonal wrasse settlement. I randomly chose $1050-\mathrm{m}^{2}$ quadrats $(5 \times 10 \mathrm{~m})$ from each of eight randomly selected locations around the island. To census juvenile abundance, I marked the perimeters of each quadrat with nylon cord and counted all juvenile six bar wrasse (individuals with lengths $<8 \mathrm{~cm}$ ) contained within. Juvenile abundance for each location was estimated as the sum of the counts from the 10 replicate quadrats. Sampled locations varied in their distance (shoreward) away from the reef crest, and the pattern juvenile abundance across this distance-gradient was analyzed using regression.

\section{Habitat availability as sole factor?}

The spatial pattern of abundance of juvenile wrasse across the lagoon was estimated from randomly selected quadrats that varied in composition of habitat. If juvenile six bar wrasse are nonrandomly distributed across habitat types, then the observed pattern of juvenile abundance may simply reflect variability in abundance of utilized habitat types across the lagoon. To test this hypothesis, I used the following approach: (1) I quantified the habitat composition of sampled quadrats and recorded specific habitat types associated with each observed fish. (2) I calculated electivity values for both new settlers and older juveniles. (3) I defined "settlement habitat" as the unweighted aggregate of all habitat types to which six bar wrasse settled and estimated the abundance of settlement habitat at each sampled location. I then analyzed the pattern of abundance of juvenile wrasse across locations as a function of settlement habitat abundance using regression.

Quantifying habitat composition and fish associations.-Habitat composition was determined for each of the $50-\mathrm{m}^{2}$ quadrats used to estimate the pattern of abundance of juvenile wrasse and for an additional set of nine $100-\mathrm{m}^{2}$ quadrats $(10 \times 10 \mathrm{~m})$ from which daily settlement was monitored for two five-day settlement pulses. Each quadrat was divided into a square grid of points, determined by the intersections of overlaying nylon cords placed at $0.5-\mathrm{m}$ intervals along quadrat length and width axes (i.e., 200 sample points for 50$\mathrm{m}^{2}$ quadrats, 400 sample points for $100-\mathrm{m}^{2}$ quadrats). I recorded the habitat type beneath each sample point 
as a combination of reef morphology (e.g., patch reef, reef flat, or thicket) and substrate (e.g., live coral, dead coral rubble, macroalgae, damselfish algal turf, sand, or pavement) characteristics. Proportionate cover of all existing habitat types (some combinations of morphology and substrate were never observed) was estimated for each quadrat. To estimate habitat associations of juvenile wrasse, I recorded habitat types immediately beneath each fish I encountered in the surveys of abundance of juvenile wrasse. To estimate habitat associations of newly settled six bar wrasse, I monitored nine $100-\mathrm{m}^{2}$ quadrats over two separate fiveday settlement pulses (occurring in May 1997 and June 1997) and recorded all new settlers (unpigminted individuals settling the previous night) and the habitat types immediately beneath each observed individual.

Identifying juvenile and settler habitats.-Relative habitat use by juveniles and settlers was estimated using Manly's alpha (Manly et al. 1972, Chesson 1978). This measure is based on the proportion of wrasse on a given habitat type relative to their probability of associating with that habitat type under conditions of random assortment, and is calculated as:

$$
\alpha_{i}=\frac{\frac{F_{i}}{H_{i}}}{\sum_{j=1}^{n} \frac{F_{j}}{H_{j}}} \quad i=1, \ldots, n
$$

where relative habitat use $(\alpha)$ is evaluated separately for each habitat type ( 1 through $n$ ), $H$ is the proportion of surveyed habitat of a given type, $F$ is the proportion of censused fish on a given habitat type. To represent relative habitat use as a set of independent values in the form of an index ranging from -1 (never used) to +1 (exclusively used) with 0 representing neutral association, I converted $\alpha_{i}$ values to electivities $\left(\varepsilon_{i}\right)$ by

$$
\varepsilon_{i}=\frac{n \alpha_{i}-1}{(n-2) \alpha_{i}+1} \quad i=1, \ldots, n
$$

where $n$ is the number of habitat types (Chesson 1983). Electivities were calculated separately for juveniles and for settlers in May 1997 and June 1997.

Abundance of settlement habitat.-I classified "settlement habitat" as the unweighted aggregate of all habitat types used by new settlers (i.e., all habitat types with $\varepsilon>-1)$. For each $50-\mathrm{m}^{2}$ quadrat used to estimate juvenile abundance, percent cover of settlement habitat was multiplied by 50 to estimate its abundance (measured in square meters). I estimated total abundance of settlement habitat for each of the eight sampled locations as the summed abundances from the 10 replicate quadrats within each location. Abundance of settlement habitat varied across sampled locations, and patterns of (1) settlement habitat abundance as a function of distance from the reef crest, and (2) abundance of juveniles as a function of settlement habitat abundance were analyzed using regression.

\section{Settlement as sole factor?}

The pattern of abundance of juvenile wrasse across the lagoon may indicate a pattern of depleting settlement with increased distance from the larval source (the source being oceanic water advected into the lagoon at the reef crest). To evaluate whether such a pattern of settlement could explain the pattern of abundance of juveniles across the lagoon, I conducted daily censuses of new settlers (fish younger than one day old) arriving to 96 patch reefs over three separate fiveday settlement pulses (occurring in May 1996, May 1997, and June 1997). Patch reefs selected for observation reflected reef sizes and characteristics typically used by newly settled and juvenile six bar wrasse: all were of comparable size $\left(4.02 \mathrm{~m}^{2} \pm 1.67\right.$, mean \pm 1 $\mathrm{SD})$, topographic complexity, and composed of damselfish algal turf (primary settlement habitat as determined by electivities). Selected patch reefs were isolated from nearest neighboring reefs by $>3 \mathrm{~m}$ of reef flat (sand or pavement substrates, habitat types never used by settlers or juveniles; from electivities). All patch reefs were located on the north shore of the island: 48 patch reefs were located $\sim 250 \mathrm{~m}$ from the reef crest; the remaining 48 reefs were located $\sim 800$ $\mathrm{m}$ from the reef crest. Settler densities were estimated as the number of new (unpigmented) individuals counted on a patch reef over each five-day pulse divided by the area of the patch reef. Differences in settler densities between patch reefs located $250 \mathrm{~m}$ from the reef crest and $800 \mathrm{~m}$ from the reef crest were compared separately for May 1996, May 1997, and June 1997 sampling periods. I used the GLM procedure of SAS to conduct analysis of variance tests that treated distance from the reef crest as a fixed factor (SAS Institute 1990).

\section{Separating effects of habitat and distance}

I manipulated abundance of settlement habitat to uncouple effects of settlement habitat from distance onshore of the reef crest. I randomly selected fifteen 100$\mathrm{m}^{2}$ quadrats $(10 \times 10 \mathrm{~m})$ from the lagoon on the north shore of Moorea. All quadrats were located either at $250 \mathrm{~m}$ from the reef crest $(n=9)$ or $800 \mathrm{~m}$ from the reef crest $(n=6)$. Ambient abundance of primary settlement habitat (damselfish turf on patch reefs) was estimated for each quadrat using the methods described. Because abundance of settlement habitat differed among quadrats across the two distances, I randomly selected a subset of quadrats at the 250 -m distance and reduced abundance of primary settlement habitat to mean levels measured among quadrats 800 $\mathrm{m}$ from the reef crest. Settlement habitat was reduced by removing damselfish with hand nets and scouring associated algal turf from patch reefs with a wire brush. Subsequent daily settlement to each quadrat was monitored during a five-day settlement pulse in June of 1997 using the methods described. I used the GLM 
procedure of SAS to test for differences in total settlement among quadrats at (1) $250 \mathrm{~m}$ with ambient settlement habitat, (2) $250 \mathrm{~m}$ with reduced settlement habitat, and (3) $800 \mathrm{~m}$ with ambient settlement habitat using a fixed factor analysis of variance (SAS Institute 1990).

\section{Habitat availability, settlement, and postsettlement losses as combined factors?}

Habitat plus settlement.-To evaluate whether the pattern of settlement to units of settlement habitat coupled with the pattern of abundance of settlement habitat across the lagoon could account for the pattern of abundance of juvenile wrasse, I calculated expected abundances of juveniles at fixed distances from the reef crest (either 250 or $800 \mathrm{~m}$ ) and compared them to observed abundances. Calculations consisted of multiplying abundance of settlement habitat by the settler densities per unit settlement habitat at each of the fixed distances. Settler densities (in units of no. fish per square meter of settlement habitat) were calculated from mean settler densities at each fixed distance summed over the three measured settlement pulses. Because abundances of settlement habitat (in units of square meters of settlement habitat per $500 \mathrm{~m}^{2}$ lagoon bottom) were sampled across a gradient of distances from the reef crest, estimates of settlement habitat abundance for the fixed distances were obtained from the regression of settlement habitat abundance on distance. Observed abundance of juvenile wrasse was similarly measured across a gradient of distance from the reef crest, hence the abundances of juveniles at fixed distances were estimated from the fitted regression. Because patterns of juvenile abundance, settlement habitat abundance, and settlement were documented in different years, comparisons of expected and actual abundances of juveniles across distances were conducted on a relative scale. This was accomplished by comparing the ratio of observed abundance at the two fixed distances (e.g., Observed $_{250 \mathrm{~m}}$ : Observed $_{800 \mathrm{~m}}$ ) to the ratio of expected abundance at the two fixed distances Expected $_{250 \mathrm{~m}}$ : Expected $_{800 \mathrm{~m}}$ ).

Habitat plus settlement plus postsettlement losses.I estimated postsettlement losses by following the fate of three cohorts settling to 96 patch reefs over 90 postsettlement days. Young six bar wrasse on Moorea are relatively sedentary on primary settlement habitat, with punctuated monthly settlement events, and exhibit an excellent relationship between size and age (Shima $1999 b$ ). These attributes facilitate estimation of early postsettlement losses (emigration plus mortality) of a cohort as the difference between the initial number of settlers and the number of individuals of appropriate size (from size-age regression) $90 \mathrm{~d}$ after settlement (see Shima 1999b).

I incorporated estimated losses with patterns of settlement and settlement habitat abundance to calculate the expected abundances of juveniles at fixed distances from the reef crest (either 250 or $800 \mathrm{~m}$ ). Expected abundance was estimated by multiplying recruit densities (mean settlers minus mean losses, each summed over three settlement pulses) by abundance of settlement habitat at each of the fixed distances from the reef crest. Comparisons among expected and observed abundances were conducted on a relative scale by comparing the ratio of observed abundance at the two fixed distances (e.g., Observed ${ }_{250 \mathrm{~m}}:$ Observed $_{800 \mathrm{~m}}$ ) to the ratio of expected abundance at the two fixed distances (Expected $_{250 \mathrm{~m}}$ : Expected $_{800 \mathrm{~m}}$ ).

Additionally, I evaluated the relationship between mean per capita loss rates and mean initial densities at each fixed distance from the reef crest, for each of three settlement events. I calculated mean per capita loss rates (assessed over the first $90 \mathrm{~d}$ ) as $(S-R) / S$, where $S$ is the mean number of settlers arriving to 48 patch reefs at a given distance from the reef crest (either 250 or $800 \mathrm{~m}$ ) during a given settlement pulse (May 1996, May 1997, or June 1997); $R$ is the number of individuals of appropriate size averaged over the same sets of patch reefs. Individual reefs receiving zero settlers were excluded from the calculation of per capita losses. Mean per capita loss rates were evaluated as a function of mean initial settler density using the GLM procedure of SAS (SAS Institute 1990). For purposes of presentation, this approach simultaneously explores spatial (i.e., distances across the lagoon) and temporal (i.e., across three settlement pulses) density dependence in per capita losses; consequently, it should be noted that the fitted regression suffers from a lack of independence among points. However, a more detailed analysis of density dependence in these data is presented elsewhere (Shima 2001), and suggests that this less formal analysis is robust.

\section{RESUlts}

\section{Pattern of abundance of juvenile wrasse across the lagoon}

Abundance of juvenile wrasse declined with distance from the reef crest (Fig. 1A). The pattern of decline appeared to be exponential $\left(y=178.79 e^{-0.002 x}, r^{2}=\right.$ 0.95 ), indicating that abundance of juvenile wrasse decreased by a constant proportion with incremental increases in distance from the reef crest.

\section{Habitat availability as sole factor?}

Expressed as electivities, patterns of habitat use by new settlers (Fig. 2A) closely matched those used by older juveniles (Fig. 2B), and suggest that ontogenetic shifts in habitat use during this period were not dramatic. Settler electivities for damselfish turf on patch reefs were strong and constant for two pulses that differed in intensity by nearly an order of magnitude (mean settlement for May 1997, 3.78 individuals/100 $\mathrm{m}^{2}$; June 1997, 28.88 individuals $/ 100 \mathrm{~m}^{2}$ ). The strong and consistent overuse of damselfish turf on patch reefs 

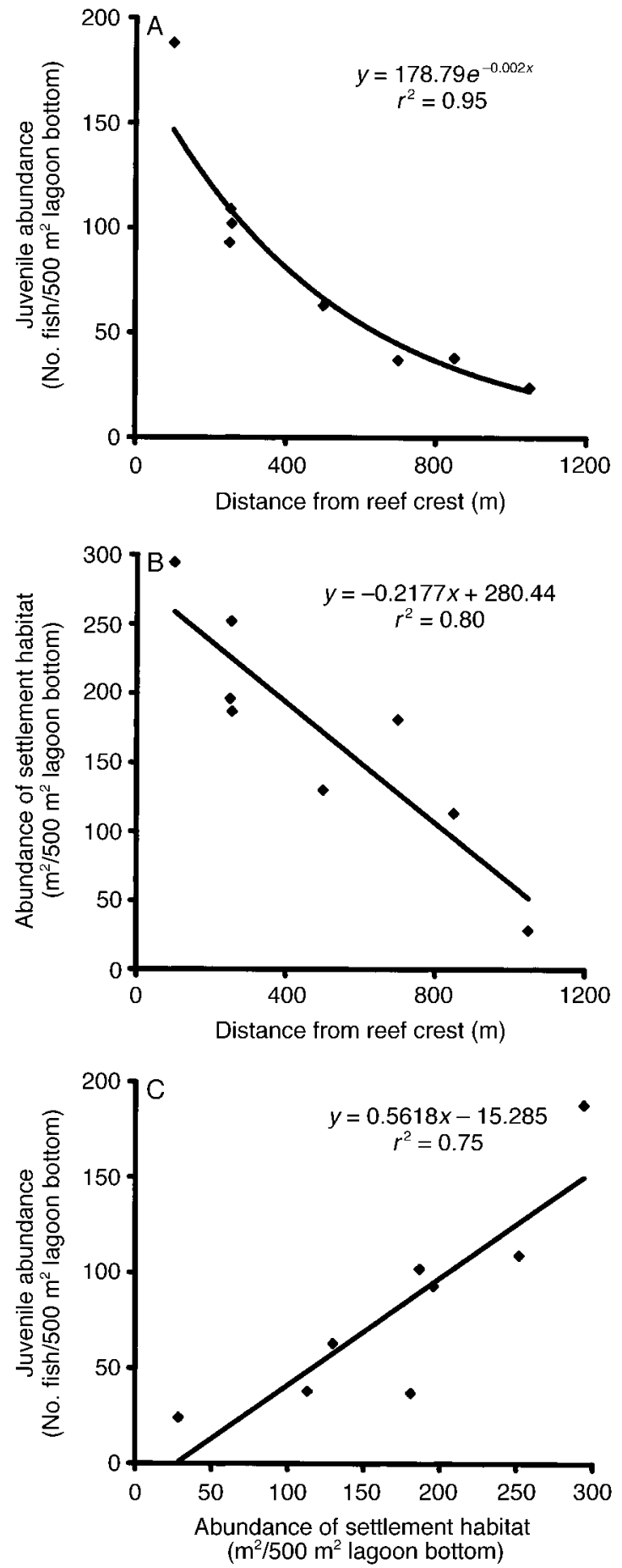

FIG. 1. Patterns of abundance of (A) juvenile six bar wrasse and (B) their settlement habitat across the lagoon surrounding Moorea, French Polynesia. (C) The relationship between wrasse abundance and settlement habitat. (A) The total numbers of juveniles counted in $500 \mathrm{~m}^{2}$ of lagoon bottom (summed from 10 random $50-\mathrm{m}^{2}$ quadrats) at each of eight random locations that vary in their distance from the reef crest are given. (B) The total abundance $\left(\mathrm{m}^{2}\right)$ of settlement habitat ( $\varepsilon>-1$, in Fig. 2) per $500 \mathrm{~m}^{2}$ of lagoon bottom for each of these same locations is presented. Details of the fitted regressions are also given. suggests that this represents primary settlement habitat of six bar wrasse. Electivities for other habitat types to which six bar wrasse settled (live coral on patch reefs, rubble on patch reefs, and damselfish turf on reef flats) increased with magnitude of the settlement pulse, suggesting that these may represent secondary (i.e., overflow) settlement habitats for six bar wrasse. No settlers were observed in macroalgae on patch reefs, or on reef flats comprised of coral, rubble, macroalgae, sand, or pavement. Thickets are generally rare around Moorea and were not present in quadrats used to estimate settler electivities. An aggregate of all habitat types settled upon by six bar wrasse was used to estimate settlement habitat.

The abundance of settlement habitat declined sharply with increasing distance from the reef crest across sam-

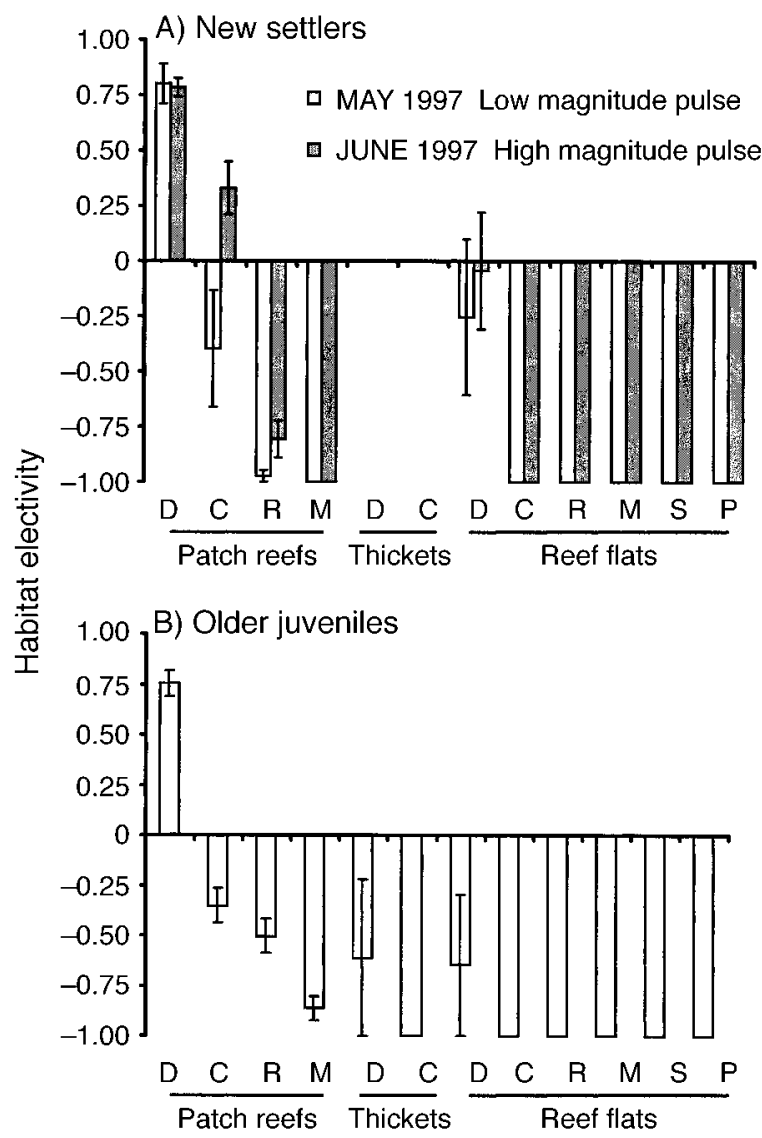

FIG. 2. Patterns of habitat usage by (A) six bar wrasse at settlement, and (B) as older juveniles. Habitat usage is presented as electivities, $\varepsilon$ (means $\pm 1 \mathrm{SE}$ ), which range from -1 (least associated) to +1 (most associated) for each substrate type (D, damselfish algal turf; $\mathrm{C}$, live coral; $\mathrm{R}$, dead coral rubble; M, macroalgae; S, sand; P, pavement) on either patch reefs, thickets, or reef flats. Electivities of new settlers (fish settling on the previous night) were calculated separately for a low-magnitude pulse of settlement (May 1997) and for a high-magnitude pulse of settlement (June 1997). Electivities for juveniles were calculated for all juveniles of ages 1-8 mo postsettlement. 
pled locations $\left(r^{2}=0.80\right.$, Fig. 1B). The abundance of juvenile wrasse increased with the abundance of settlement habitat across sampled locations (Fig. 1C). A linear regression model explained $\sim 75 \%$ of the variation in abundance of juvenile wrasse and suggests the abundance of settlement habitat alone could account for the spatial pattern of abundance of juvenile wrasse.

\section{Settlement as sole factor?}

Larval replenishment of lagoon populations on Moorea occurs from waves that break over the offshore barrier reef crest and move larvae shoreward (Dufour and Galzin 1993, Dufour et al. 1996). The exponential decline in juvenile abundance with increasing distance from the reef crest is consistent with a larval depletion hypothesis, whereby larvae settle as they drift over the reef crest and onto the reef flat, so that larval supply is depleted with increasing distance from the crest. This hypothesis predicts that densities of settlers (i.e., no. settlers per unit settlement habitat) will decline with distance from the reef crest.

Overall, I observed higher settler densities on patch reefs nearer to the reef crest (Fig. 3). Although intensity of settlement pulses varied by nearly an order of magnitude, settler densities declined significantly with distance from the reef crest in two out of three pulses (May 1996 and June 1997). The weakest settlement pulse occurred in May 1997. For this pulse, the decline in settler density with distance from the reef crest was not quite significant statistically $(P=0.064)$, but was likely biologically meaningful. The observation that settler densities generally declined with distance from the reef crest is consistent with the hypothesis that patterns of settlement alone could account for the spatial pattern of abundance of juvenile wrasse.

\section{Separating effects of habitat and distance}

Reducing abundance of primary settlement habitat in quadrats $250 \mathrm{~m}$ from the reef crest to levels observed at $800 \mathrm{~m}$ resulted in subsequent settlement of six bar wrasse that was intermediate to quadrats at $250 \mathrm{~m}$ with ambient settlement habitat and quadrats at $800 \mathrm{~m}$ with ambient settlement habitat (Fig. 4). These results suggest that both the abundance of settlement habitat and the distance from the reef crest determine settlement of six bar wrasse.

\section{Habitat availability, settlement, and postsettlement losses as combined factors?}

Habitat plus settlement.-Coupling abundance of settlement habitat with densities of settlers on settlement habitat yielded an expected abundance of juvenile wrasse $250 \mathrm{~m}$ from the reef crest that was approximately four times greater than the expected abundance at $800 \mathrm{~m}$ (Table 1). This expected ratio overestimated of the actual pattern of abundance of juvenile wrasse, because only three times as many fish were observed
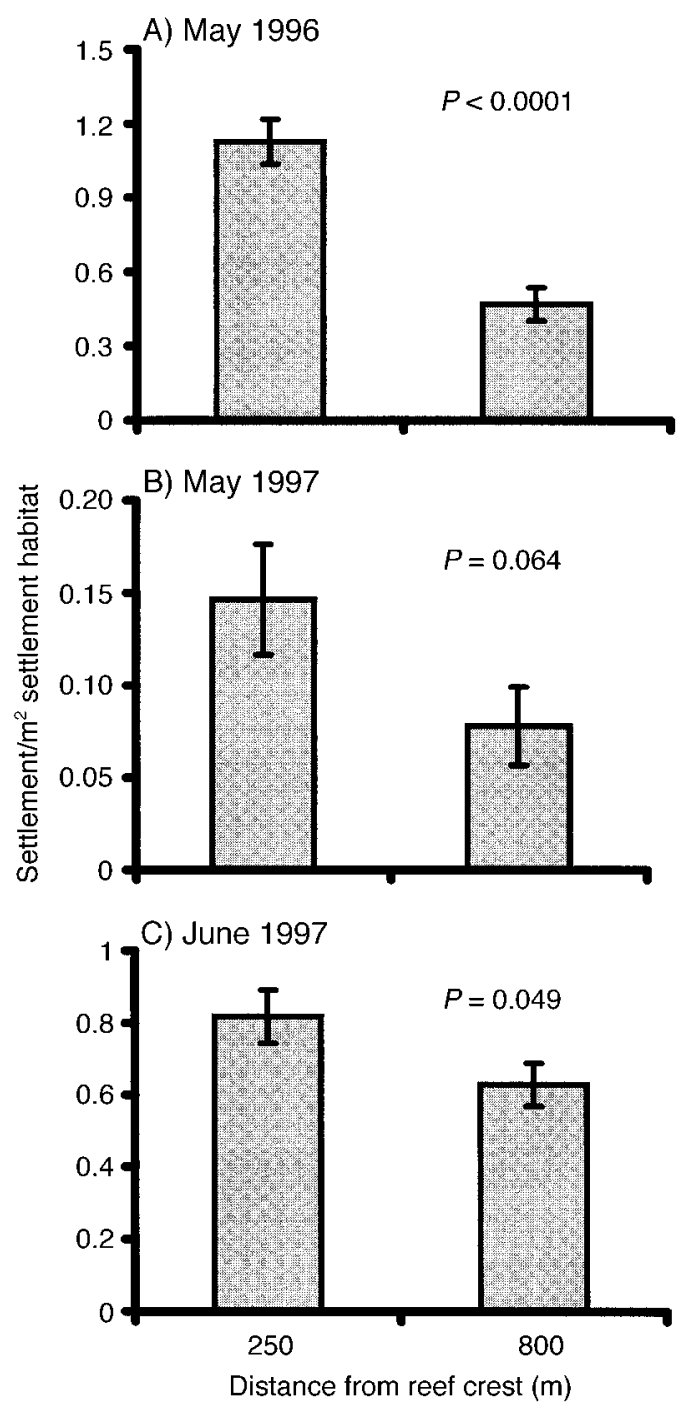

FIG. 3. Pattern of six bar wrasse settlement across the lagoon. Given are the mean settler densities ( $\pm 1 \mathrm{SE}$ ) recorded on primary settlement habitat at each of two distances from the reef crest ( $n=48$ patch reefs for each distance). Patterns of settlement were documented for three separate settlement pulses (May 1996, May 1997, and June 1997) using the same set of patch reefs.

at the $250 \mathrm{~m}$ distance relative to the $800 \mathrm{~m}$ distance (Table 1).

Habitat plus settlement plus losses.-The per capita losses of settled cohorts assessed among patch reefs and months over $90 \mathrm{~d}$ were found to be strongly density dependent (Fig. 5). Per capita losses increased with initial settler densities, hence losses varied among settlement pulses of differing magnitude (represented by differently shaped symbols) and were generally greater on reefs nearer to the reef crest (closed symbols) for a given pulse. These findings suggest that variation in settlement density of six bar wrasse through space and time can be partially offset by strong density-dependent 


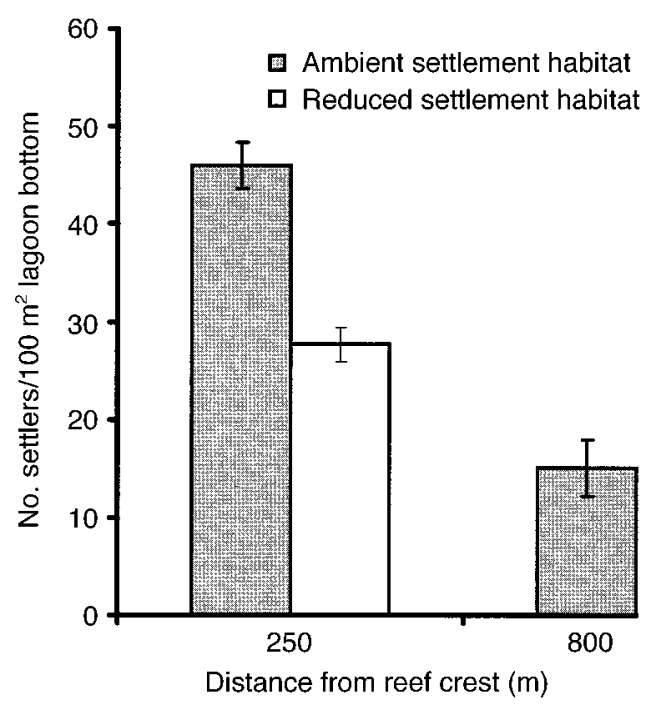

FIG. 4. Patterns of settlement (mean $\pm 1 \mathrm{SE}$ ) to $100-\mathrm{m}^{2}$ quadrats, following a field manipulation to separate effects of abundance of primary settlement habitat from distance from the reef crest. Ambient abundance of primary settlement habitat (damselfish turf on patch reefs, from Fig. 2A) at a random subset of quadrats $250 \mathrm{~m}$ from the reef crest was reduced to mean abundance of primary settlement habitat measured in quadrats $800 \mathrm{~m}$ from the reef crest. Total settlement over a five-day settlement pulse in June 1997 was compared among quadrats at (1) $250-\mathrm{m}$ distance with ambient settlement habitat, (2) 250-m distance with reduced settlement habitat, and (3) 800-m distance with ambient settlement habitat, using fixed-factor analysis of variance. Results of each treatment are significantly different from the others $(P$ $<0.05$, post hoc Tukey comparisons).

postsettlement losses. Incorporating losses with settlement and abundance of settlement habitat predicted relative abundances of juvenile wrasse at the two fixed distances (3:1) that agreed well with observed relative abundances (Table 1).

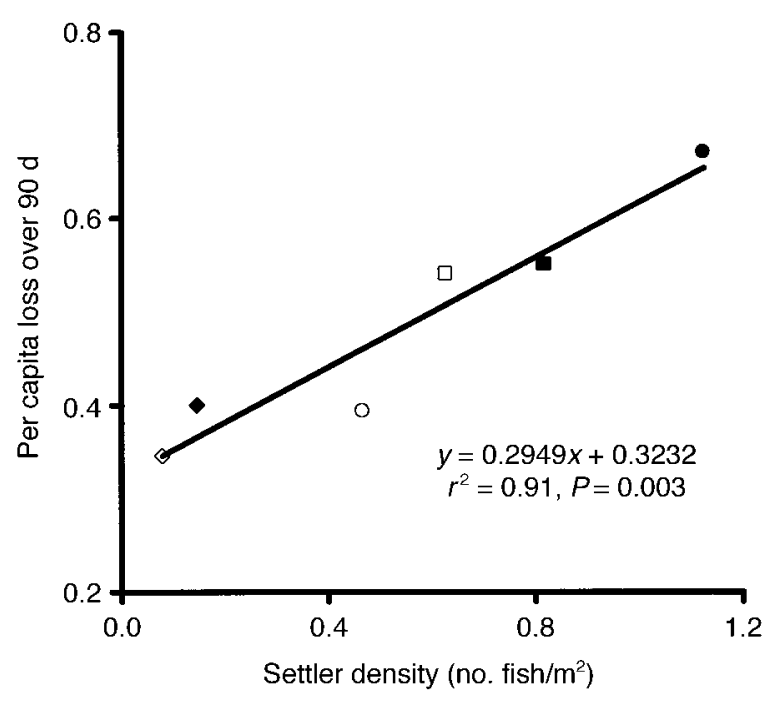

FIG. 5. Density-dependent losses of six bar wrasse over $90 \mathrm{~d}$. Mean initial settler densities on 48 patch reefs $250 \mathrm{~m}$ from the reef crest (closed symbols) and 48 patch reefs 800 $\mathrm{m}$ from the reef crest (open symbols), for each of three settlement pulses (May 1996, circles; May 1997, diamonds; June 1997, squares) are plotted against mean per capita losses from each collection of reefs/times. Details of the fitted linear regression are given.

\section{DISCUSSION}

Workers in marine reef systems have historically approached questions concerning patterns of abundance from the perspective of population limitation (Caley et al. 1996). This framework, which implies that a single factor alone is responsible for limiting population size (e.g., recruitment limitation, sensu Doherty [1981]), has produced numerous studies that use correlational evidence to attribute patterns of abundance of reef fishes to single-factor explanations (reviewed in Doherty [1991], Hixon [1991], Jones [1991], Williams [1991]).

Table 1. Dissecting the separate and joint effects of utilized habitat, settlement, and postsettlement losses on the population sizes of juvenile wrasse at locations 250 and $800 \mathrm{~m}$ from the reef crest, including approximate ratios of values from 250 and $800 \mathrm{~m}$.

\begin{tabular}{|c|c|c|c|c|c|c|}
\hline $\begin{array}{l}\text { Distance from } \\
\text { reef crest }\end{array}$ & $\begin{array}{c}\text { Pattern of } \\
\text { abundance } \\
\text { of juveniles } \dagger\end{array}$ & $\begin{array}{c}\text { Habitat } \\
\text { abundance } \ddagger\end{array}$ & Settlement§ & $\begin{array}{c}\text { Total } \\
\text { fish density\| }\end{array}$ & $\begin{array}{l}\text { Losses over } \\
90 \mathrm{~d} \mathbb{I}\end{array}$ & $\begin{array}{c}\text { Total } \\
\text { fish density\# }\end{array}$ \\
\hline $250 \mathrm{~m}$ & 108 & 226 & 2.0 & 452 & 1.3 & 158 \\
\hline $800 \mathrm{~m}$ & 36 & 106 & 1.1 & 117 & 0.6 & 53 \\
\hline Ratio $(250 \mathrm{~m}: 800 \mathrm{~m})$ & $3: 1$ & $2: 1$ & $2: 1$ & $4: 1$ & $2: 1$ & $3: 1$ \\
\hline
\end{tabular}

Notes: All values are as observed, except where noted. Estimates of juvenile abundance and habitat availability were derived from regressions (Figs. 1 and 2, respectively). Joint effects (e.g., expected total fish density) were calculated from estimates of habitat, settlement, and losses.

$\dagger$ Units: no. fish $/ 500 \mathrm{~m}^{2}$ lagoon bottom.

\$ Units: no. $\mathrm{m}^{2}$ settlement habitat $/ 500 \mathrm{~m}^{2}$ lagoon bottom.

$\S$ Units: no. fish $/ \mathrm{m}^{2}$ settlement habitat. Settlement values were derived from daily censuses of 96 patch reefs composed of standardized habitat units (primary habitat utilized by settlers). Values were obtained by summing over three pulses.

|| Units: no. fish $/ 500 \mathrm{~m}^{2}$ lagoon bottom. Expected values are reported, given habitat and settlement.

II Units: no. fish $/ \mathrm{m}^{2}$ settlement habitat. Losses were derived from repeated surveys of settled cohorts through time. Values were obtained by summing over three pulses.

\# Units: no. fish $/ 500 \mathrm{~m}^{2}$ lagoon bottom. Expected values are reported, given habitat, settlement, and losses. Values were obtained from data accumulated from three random pulses. 
In this study, I demonstrate how correlations can simultaneously support two separate single-factor explanations (habitat or settlement) for structuring spatial patterns of abundance of a reef fish. I found that six bar wrasse appear to utilize specific habitat types for settlement within the lagoon, and that these habitat associations persist into the older juvenile stages. The abundance of settlement habitat was an excellent predictor of spatial variation in juvenile six bar wrasse abundance across the lagoon of Moorea, and similar findings have been used elsewhere as support for the idea that certain reef resources are the single factor shaping population sizes of reef fishes (Bell and Galzin 1984, Bell et al. 1985, Roberts and Ormond 1987, Levin 1991). Likewise, spatial variation in settler densities matched the spatial pattern of abundance of juvenile wrasse measured across the lagoon, and many studies have used similar findings to implicate larval settlement (or recent recruitment) as the single factor that shapes patterns of local abundance of reef fishes (Victor 1986b, Milicich et al. 1992, Doherty and Fowler 1994).

Because the pattern of abundance of settlement habitat covaried with the presumed pattern of larval delivery across the lagoon, I manipulated settlement habitat to uncouple these two factors with respect to distance from the reef crest. Results of this manipulation implicated both the abundance of settlement habitat and its distance from the reef crest as important determinants of subsequent patterns of settlement. Although few workers would disagree that patterns of settlement and abundance of settlement habitat can both contribute to population sizes of reef fishes, the joint effects of these two factors failed to describe the pattern of abundance of juvenile six bar wrasse without also considering a third factor-postsettlement losses-which were density dependent and substantially modified patterns of settlement. Hence, while single-factor explanations appear to be easily supported by data sets typically collected by marine researchers, inferences of multifactorial causation may be falsely refuted when incomplete sets of important factors are considered. These results demonstrate how pluralistic approaches considering inputs, resources, and losses are necessary to discern multifactorial causation of patterns of abundance.

Pluralistic studies of more than two factors are rare in marine reef systems. Many studies have considered interactive effects of habitat and postsettlement factors (e.g., Thresher 1983, Shulman and Ogden 1987, Jones 1988, Connell and Jones 1991, Wellington 1992, Hixon and Beets 1993, Tupper and Boutilier 1995, 1997). Many others have explored relationships between settlement and postsettlement losses (e.g., Jones 1990, Forrester 1990, Schmitt and Holbrook 1996, 1999a, $b$, Hixon and Carr 1997, Steele 1997a, b, Caselle 1999, Shima 2001). Additionally, relationships between settlement and available habitat have been investigated (e.g., Tolimieri 1995, Caselle and Warner 1996, Beu- kers and Jones 1997). However, I know of no previously published reef study that has simultaneously evaluated patterns of variation in habitat, settlement, and postsettlement losses, along with their joint consequences for patterns of abundance of older life stages (see Herrera et al. [1994] for terrestrial plant example).

In this study, two single-factor explanations (settlement and habitat) and a multifactorial explanation (habitat plus settlement plus losses) appeared to account for the pattern of abundance of juvenile wrasse, because patterns of settlement, habitat, and losses were positively spatially correlated. Such correlations among multiple factors appear to be common in ecological and evolutionary studies (Mitchell-Olds and Shaw 1987, James and McCulloch 1990, Petraitis et al. 1996, Thomson et al. 1996, Beukers and Jones 1997), suggesting that in many instances multiple explanations for patterns of abundance (both single-factor and multifactorial) may be supported, depending upon the particular data initially earmarked for collection. In marine reef systems, where fishes often utilize habitats of biotic origin (e.g., corals, kelps, anemones; Sale 1972, Hanlon and Kaufman 1976, Shulman 1985, Carr 1989, 1994, Ebeling and Hixon 1991, Levin 1991, Anderson 1994), spatial patterns of settlement for a focal fish species may frequently covary with the abundance of its biotic habitat and the abundance of its predators. This is because the local recruitment rates and/or growth rates of many reef organisms are likely to be influenced by common sets of physical oceanographic features (e.g., Wolanski and Hamner 1988, Kingsford 1990, Kingsford et al. 1991). In these systems, single factors (settlement, habitat, or predators) that are assessed in isolation may each appear sufficient to explain spatial patterns of abundance, and consequently, multifactorial influences may be obscured.

As most field ecologists are limited to some degree by time and funding, they often must make decisions about the detail and breadth of data to be collected. As evidenced by this study, such decisions can substantially influence inferences drawn from correlational data, and may misrepresent multifactorial causation in favor of more easily detected single-factor explanations. Multifactorial causation of ecological and evolutionary patterns appears to be a common phenomenon, but it is likely to be missed if only single factors (or a subset of factors) are considered. This holds true regardless of whether inferences are based on correlational evidence or on single-factor manipulative experiments that confirm causal linkages. A multifactorial mind-set is imperative for uncovering the influence of multiple interacting factors on ecological and evolutionary patterns.

\section{ACKNOWLEDGMENTS}

I wish to thank A. Ammann, S. Kleinschmidt, and C. Shuman, for their valuable assistance in the field. R. Bolser, E. Borer, A. Brooks, J. Byers, J. Caselle, S. Gaines, M. Hixon, S. Holbrook, N. Phillips, R. Schmitt, E. Silldorff, S. Swearer, 
and two anonymous reviewers provided many helpful comments on versions of this manuscript. I particularly wish to acknowledge my Ph.D. committee members, R. Schmitt, S. Holbrook, and S. Gaines. Many thanks to F. Murphy, S. Strand, T. You-Sing, and J. You-Sing of the University of California-Berkeley Gump Biological Station for their logistical support, assistance, and hospitality. M. Arnold, K. Seydel, and B. Williamson provided valuable logistical support from University of California-Santa Barbara. Funding for this work was provided by a Research Training Grant and the Graduate Research Trainee Program in Spatial Ecology (NSF BIR94-13141 and NSF GER93-54870, both to W. Murdoch), a National Science Foundation (NSF) award to R. Schmitt and S. Holbrook (OCE 99-10677), the Lerner-Gray Fund for Marine Research (American Museum of Natural History), Sigma Xi, and the Raney Award (American Society of Ichthyologists and Herpetologists). This paper is contribution No. 69 of the Gump South Pacific Biological Station.

\section{Literature Cited}

Anderson, T. W. 1994. Role of macroalgal structure in the distribution and abundance of a temperate reef fish. Marine Ecology Progress Series 113:279-290.

Bell, J. D., and R. Galzin. 1984. Influence of live coral cover on coral-reef fish communities. Marine Ecology Progress Series 15:265-274.

Bell, J. D., M. L. Harmelin-Vivien, and R. Galzin. 1985. Large scale spatial variation in abundance of butterflyfishes (Chaetodontidae) on Polynesian reefs. Proceedings of the Fifth International Coral Reef Symposium 5:421-426.

Beukers, J. S., and G. P. Jones. 1997. Habitat complexity modifies the impact of piscivores on a coral reef fish population. Oecologia 114:50-59.

Brody, A. K. 1997. Effects of pollinators, herbivores, and seed predators on flowering phenology. Ecology 78:16241631 .

Caley, M. J., M. H. Carr, M. A. Hixon, T. P. Hughes, G. P. Jones, and B. A. Menge. 1996. Recruitment and the local dynamics of open marine populations. Annual Reviews of Ecology and Systematics 27:477-500.

Carr, M. H. 1989. Effects of macroalgal assemblages on the recruitment of the temperate zone reef fishes. Journal of Experimental Marine Biology and Ecology 126:59-76.

Carr, M. H. 1994. Effects of macroalgal dynamics on recruitment of a temperate reef fish. Ecology 75:1320-1333.

Caselle, J. E. 1999. Early post-settlement mortality in a coral reef fish and its effect on local population size. Ecological Monographs 69:177-194.

Caselle, J. E., and R. R Warner. 1996. Variability in recruitment of coral reef fishes: the importance of habitat at two spatial scales. Ecology 77:2488-2504.

Chesson, J. 1978. Measuring preference in selective predation. Ecology 59:211-215.

Chesson, J. 1983. The estimation and analysis of preference and its relationship to foraging models. Ecology 64:12971304.

Connell, J. H. 1961. The influence of interspecific competiton and other factors on the distribution of the barnacle Chthamalus stellatus. Ecology 42:710-723.

Connell, S. D., and G. P. Jones. 1991. The influence of habitat complexity on post-recruitment processes in a temperate reef fish population. Journal of Experimental Marine Biology and Ecology 151:271-294.

Doherty, P. J. 1981. Coral reef fishes: recruitment-limited assemblages? Proceedings of the Fourth International Coral Reef Symposium, Manila 2:465-670.

Doherty, P. J. 1991. Spatial and temporal patterns in recruitment. Pages 261-293 in P. F. Sale, editor. The ecology of fishes on coral reefs. Academic Press, San Diego, California, USA.

Doherty, P., and A. Fowler. 1994. An empirical test of re- cruitment limitation in a coral reef fish. Science 263:935939.

Dufour, V., and R. Galzin. 1993. Colonization patterns of reef fish larvae to the lagoon at Moorea Island, French Polynesia. Marine Ecology Progress Series 102:143-152.

Dufour, V., E. Riclet, and A. Lo-Yat. 1996. Colonization of reef fishes at Moorea Island, French Polynesia: temporal and spatial variation of the larval flux. Australian Journal of Marine and Freshwater Research 47:413-422.

Ebeling, A. W., and M. A. Hixon. 1991. Tropical and temperate reef fishes: comparison of community structures. Pages 509-563 in P. F. Sale, editor. The ecology of fishes on coral reefs. Academic Press, San Diego, California, USA.

Folt, C. L., C. Y. Chen, M. V. Moore, and J. Burnaford. 1999. Synergism and antagonism among multiple stressors. Limnology and Oceanography 44:864-877.

Forrester, G. E. 1990. Factors influencing the juvenile demography of a coral reef fish. Ecology 71:1666-1681.

Galzin, R., and J. P. Pointier. 1985. Moorea Island, Society Archipelago. Pages 75-101 in B. Delesalle, R. Galzin, and B. Salvat, editors. Fifth International Coral Reef Congress, Tahiti. Volume 1. Coral Reef Congress, Tahiti, French Polynesia.

Hanlon, R. T., and L. Kaufman. 1976. Associations of seven West Indian reef fishes with sea anemones. Bulletin of Marine Science 26:225-232.

Herrera, C. M. 1991. Dissecting factors responsible for individual variation in plant fecundity. Ecology 72:14361448.

Herrera, C. M. 1992. Historical effects and sorting processes as explanations for contemporary ecological patterns: character syndromes in Mediterranean woody plants. The American Naturalist 140:421-446.

Herrera, C. M., P. Jordano, L. Lopez-Soria, and J. A. Amat. 1994. Recruitment of a mast-fruiting, bird-dispersed tree: bridging frugivore activity and seedling establishment. Ecological Monographs 64:315-344.

Hixon, M. A. 1991. Predation as a process structuring coral reef fish communities. Pages 475-500 in P. F. Sale, editor. The ecology of fishes on coral reefs. Academic Press, San Diego, California, USA.

Hixon, M. A., and J. P. Beets. 1993. Predation, prey refuges, and the structure of coral reef fish assemblages. Ecological Monographs 63:77-101.

Hixon, M. A., and M. H. Carr. 1997. Synergistic predation, density dependence, and population regulation in marine fish. Science 277:946-949.

Houle, G. 1998. Seedling dispersal and seedling recruitment of Betula alleghaniensis: spatial inconsistency in time. Ecology 79:807-818.

James, F. C., and C. E. McCulloch. 1990. Multivariate analysis in ecology and systematics: Panacea or Pandora's box? Annual Reviews of Ecology and Systematics 21:129-166.

Jones, G. P. 1988. Experimental evaluation of the effects of habitat structure and competitive interactions on juveniles of two coral reef fishes. Journal of Experimental Marine Biology and Ecology 123:115-126.

Jones, G. P. 1990. The importance of recruitment to the dynamics of a coral reef fish population. Ecology 71:16011698.

Jones, G. P. 1991. Postrecruitment processes in the ecology of coral reef fish populations: a multifactorial perspective. Pages 294-328 in P. F. Sale, editor. The ecology of fishes on coral reefs. Academic Press, San Diego, California, USA.

Kingsford, M. J. 1990. Linear oceanographic features: a focus for research on recruitment processes. Australian Journal of Ecology 15:391-401.

Kingsford, M. J., E. Wolanski, and J. H. Choat. 1991. Influ- 
ence of tidally-induced fronts and langmuir circulations on the distribution and movements of presettlement fishes around a coral reef. Marine Biology 109:167-180.

Levin, P. S. 1991. Effects of microhabitat on recruitment variation in a Gulf of Maine reef fish. Marine Ecology Progress Series 75:183-189.

Manly, B. F. J., P. Miller, L. M. Cook. 1972. Analysis of a selective predation experiment. The American Naturalist 106:719-736.

Milicich, M. J., M. G. Meekan, and P. J. Doherty. 1992. Larval supply: a good predictor of recruitment of three species of reef fish (Pomacentridae). Marine Ecology Progress Series 86:153-166.

Mitchell-Olds, T., and R. Shaw. 1987. Regression analysis of natural selection: statistical inference and biological interpretation. Evolution 41:1149-1161.

Paine, R. T. 1966. Food web complexity and species diversity. The American Naturalist 100:65-75.

Petraitis, P. S., A. E. Dunham, and P. H. Niewiarowski. 1996. Inferring multiple causality: the limitations of path analysis. Functional Ecology 10:421-431.

Quinn, J. F., and A. E. Dunham. 1983. On hypothesis testing in ecology and evolution. The American Naturalist 122: 602-617.

Roberts, C. M., and R. F. G. Ormond. 1987. Habitat complexity and coral reef fish diversity and abundance on Red Sea fringing reefs. Marine Ecology Progress Series 41:1-8.

Sale, P. F. 1972. Influence of corals in the dispersion of the pomacentrid fish, Dascyllus aruanus. Ecology 53:741-744.

Sale, P. F. 1991. Reef fish communities: open nonequlibrial systems. Pages 564-598 in P. F. Sale, editor. The ecology of fishes on coral reefs. Academic Press, San Diego, California, USA.

SAS Institute. 1990. SAS/Stat User's Guide, Version 6. Fourth edition. SAS Institute. Cary, North Carolina, USA.

Schmitt, R. J., and S. J. Holbrook. 1996. Local-scale patterns of larval settlement in a planktivorous damselfish-do they predict recruitment? Australian Journal of Marine and Freshwater Research 47:449-463.

Schmitt, R. J., and S. J. Holbrook. 1999a. Early mortality of juvenile damselfish: implications for assessing the processes that determine patterns of abundance. Ecology 80: $35-50$

Schmitt, R. J., and S. J. Holbrook. 1999b. Quantifying the effects of multiple processes on local abundance: a cohort approach for open populations. Ecology Letters 2:294-303.

Shima, J. S. 1999a. An evaluation of the processes that influence variability in abundance of a coral reef fish. Dissertation. University of California-Santa Barbara, California, USA.

Shima, J. S. 1999b. Variability in relative importance of determinants of reef fish recruitment. Ecology Letters 2:304310.

Shima, J. S. 2001. Regulation of local populations of a coral reef fish via joint effects of density- and number-dependent mortality. Oecologia 126:58-65.

Shulman, M. J. 1985. Recruitment of coral reef fishes: effects of distribution of predators and shelter. Ecology 66:10561066.

Shulman, M. J., and J. C. Ogden. 1987. What controls tropical reef fish populations: recruitment or benthic mortality? An example in the Caribbean reef fish Haemulon flavolineatum. Marine Ecology Progress Series 39:233-242.

Steele, M. A. 1997a. Population regulation by post-settlement mortality in two temperate reef fish. Oecologia 112: $64-74$

Steele, M. A. 1997b. The relative importance of processes affecting recruitment of two temperate reef fishes. Ecology 78:129-145.

Thomson, J. D., G. Weiblen, B. A. Thomson, S. Alfaro, and P. Legendre. 1996. Untangling multiple factors in spatial distributions: lilies, gophers, and rocks. Ecology 77:16981715.

Thresher, R. E. 1983. Habitat effects on reproductive success in the coral reef fish Acanthocromis polyacanthus (Pomacentridae). Ecology 64:1184-1199.

Tolimieri, N. 1995. Effects of microhabitat characteristics on the settlement and recruitment of a coral reef fish at two spatial scales. Oecologia 102:52-63.

Tupper, M., and R. W. Boutilier. 1995. Effects of habitat on settlement, growth, and post-settlement survival of Atlantic Cod (Gadus morhua). Canadian Journal of Fisheries and Aquatic Sciences 52:1834-1841.

Tupper, M., and R. W. Boutilier. 1997. Effects of habitat on settlement, growth, and predation risk and survival of a temperate reef fish. Marine Ecology Progress Series 151: 225-236.

Victor, B. C. 1986a. Duration of the planktonic larval stage of one hundred species of Pacific and Atlantic wrasses (family Labridae). Marine Biology 90:317-326.

Victor, B. C. 1986b. Larval settlement and juvenile mortality in a recruitment-limited coral reef fish population. Ecological Monographs 56:1435-1460.

Warner, R. R., and T. P. Hughes. 1988. The population dynamics of reef fishes. Proceedings of the Sixth International Coral Reef Symposium 1:149-155.

Welden, C. W., and W. L. Slauson. 1986. The intensity of competition versus its importance: an overlooked distinction and some implications. Quarterly Review of Biology 61:23-44.

Wellington, G. M. 1992. Habitat selection and juvenile persistence control the distribution of two closely related Caribbean damselfishes. Oecologia 90:500-508.

Williams, D. McB. 1991. Patterns and processes in the distribution of coral reef fishes. Pages 437-474 in P. F. Sale, editor. The ecology of fishes on coral reefs. Academic Press, San Diego, California, USA.

Wolanski, E., and W. M. Hamner. 1988. Topographically controlled fronts in the ocean and their biological influence. Science 241:177-181. 